\title{
FisURAS EN NARRATIVAS ROMÁNTICAS Y COMUNIDADES IMAGINADAS: MaRÍA (1867) DE JORGE ISAACS (1837-1895) y ÚRSULA (1859) DE FIRMINA Dos ReIS (1825-1917)
}

\author{
Juana Sañudo Caicedo ${ }^{1}$ \\ Universidad Federal de São Carlos, Brasil
}

\begin{abstract}
Resumen: En el presente trabajo se parte del concepto comunidades imaginadas de Benedict Anderson y su relación con el Romanticismo, en las obras María de Jorge Isaacs y Úrsula de Firmina dos Reis, en las que se construyen narraciones con subjetividades resistentes al poder en términos foucaultianos. Se exploran entonces las autorías en Isaacs y dos Reis: sujetos autoriales en las comunidades imaginadas en lo que fueron los Estados Unidos de Colombia y Brasil. Así, los autores desplegarán narraciones con sujetos de enunciación limitados o con capacidad de focalizar a los afrodescendientes. Es decir que, nos enfrentamos a dos lugares de habla: el hombre blanco y hacendado en decadencia con Efraín, que, no obstante, logra contar la historia de la esclava manumisa Nay, como también la narración en tercera persona que focaliza a la esclava Susana, ambas narrativas, en todo caso, enlazadas por el relato sobre la diáspora africana.
\end{abstract}

Palabras claves: Comunidades imaginadas; enunciación; resistencia; romanticismo.

Recibido: 12 diciembre de 2018

Aprobado: 22 enero de 2019

FisSURES IN ROMANTIC NARRATIVES AND IMAGINED COMMUNITIES: Mary (1867) BY JoRge IsAaCs (1837-1895) AND Úrsula (1859) BY FIRMINA Dos ReIs (1825-1917)

\footnotetext{
${ }^{1}$ Juana Sañudo-Caicedo es Licenciada en Literatura de la Universidad del Valle y Magíster en Literaturas Colombiana y Latinoamericana de la misma universidad. Obtuvo la mención meritoria por su tesis Misiá señora: Un Tributo a las genealogías femeninas y a la experiencia de leer como una mujer la imagen de la mujer (2016). Se ha desempeñado como docente de Lengua Castellana y Literatura en el ciclo del bachillerato y ha trabajado para colegios como La Arboleda, Cañaverales International School y la institución educativa pública Juan XXIII en la ciudad de Cali. "El presente trabajo fue realizado con el apoyo de la "Coordenação de Aperfeiçoamento de Pessoal de Nível Superior - Brasil (CAPES)" — Código de Financiamento 001”. Correo electrónico: juana. sanudo@correounivalle.edu.co
} 


\title{
Juana Sañudo Caicedo
}

\begin{abstract}
The present work is based on the concept of imagined communities of Benedict Anderson and his relationship with Romanticism, in the works María de Jorge Isaacs and Úrsula de Firmina dos Reis, in which narratives are constructed with subjectivities resistant to power in Foucauldian terms. The authories are then explored in Isaacs and dos Reis: authorial subjects in the imagined communities in what were the United States of Colombia and Brazil. Thus, the authors will display narrations with limited enunciation subjects or with the ability to focus on people of African descent. That is to say, we are faced with two places of speech: the white man and landowner in decline with Efraín, who, nevertheless, manages to tell the story of the manumisa slave Nay, as well as the third person narration that focuses on the slave Susana, both narratives, in any case, linked by the story about the Af-rican Diaspora.
\end{abstract}

Keywords: Enunciation; imagined communities; resistance; romanticism.

A partir de la idea del sistema literario en Latinoamérica es posible plantear esta propuesta comparativa entre las obras María (1867) de Jorge Isaacs (1837-1895) y Úrsula (1859) de Firmina dos Reis (18251917). Mismas ideas sobre el sistema literario que ya compartían los críticos literarios Ángel Rama y Antonio Cándido, bajo el entendido de la literatura como un cuerpo orgánico "en el cual se expresa una cultura y que el texto literario dialoga con las circunstancias socio históricas y culturales de su aparición, generándose así una visión continental que le da a nuestra América una cartografía de índole cultural" (Mejía 190).

Ambas obras comparten esas miradas subjetivas de diversos actores en el contexto del siglo XIX tanto en lo que fueron los Estados Unidos de Colombia como Brasil. Su tema focal será el análisis de las subjetividades expresadas en las estrategias de narración, sus lugares de habla y los intersticios por donde se escapan procesos de resistencia; en el sentido foucaultiano, en los proyectos políticos de nación o lo que llama Anderson comunidades imaginadas, ficciones homogeneizadoras $\mathrm{y}$, por lo tanto, bastiones de poder.

Las obras enmarcadas dentro del Romanticismo iban no sólo a compartir preocupaciones estéticas y lecturas de novelas europeas asumidas de manera intertextual - Átala (1801) de Chautebriand (1768-1848) o Pablo y Virginia (1787) de Jacques-Henri Bernardin de 
Saint Pierre (1737-1814) — sino a evidenciar cómo se iba a construir cada una de sus naciones y a hacer literatura: "[L]o que fueron procesos simultáneos durante esta corriente estética que mantuvo bajo una única idea el sentido de nación y sublimó diferencias y conflictos internos" (Agostinho 15). Pese a la época y a la pertenencia o marginalidad expresadas en María y Úrsula, respectivamente, nuestra lectura encuentra procesos de resistencia evidenciados en las voces narrativas que tejen las novelas. Razón por la cual se hace necesario sumergirse en cada una de sus tradiciones narrativas, para reconocerlas como afines o contrarias desde el concepto de comunidades imaginadas, es decir, lo que cada país propuso como su proyecto político en el siglo XIX como naciones relativamente nuevas y encontrar las disidencias, resistencias e intersticios desde esas estrategias narrativas. Ya sean las del narrador blanco y hacendado en la obra colombiana o en la narración en tercera persona con focalizaciones de la autoría brasilera.

\section{Romanticismo y proyecto de nación: comunidades imaginadas en María de Isaacs}

El Romanticismo se sumó al proyecto de las jóvenes naciones americanas para construir una idea homogénea que lograra promover el arraigo en cada coordenada geopolítica. Así construyeron lo que Anderson llama comunidades imaginadas,

Así pues, con un espíritu antropológico propongo la definición siguiente de la nación: una comunidad política inherentemente limitada y soberana. Es porque aun los miembros de la nación más pequeña no conocerán jamás a la mayoría de sus compatriotas, no los verán ni oirán siquiera hablar de ellos, pero en la mente de cada uno yive la imagen de su comunión (Anderson 23).

Esa necesidad de comunidad política, heredera de la Ilustración y de la Revolución Francesa y que tendría que haber fomentado, cuando menos, el compañerismo y la fraternidad racial, no se llevó a cabo durante el siglo XIX en el panorama de los Estados Unidos de Colombia ${ }^{2}$. Con todo y dentro de la ficción narrativa, Isaacs, a través de

\footnotetext{
${ }^{2}$ Conviene saber que, aunque la obra de Isaacs fue publicada en 1867 (época del Olimpo radical, de 1863 a 1886) el tiempo histórico de la novela se puede ubicar en un cronotopo posible
} 
la enunciación de Efraín y de la inclusión de cuatro capítulos en los que relata la historia de Nay, una de las esclavas de la hacienda azucarera el Paraíso, cumple con esa necesidad de construcción de una comunidad imaginada. Aunque con una profunda nostalgia por el antiguo régimen señorial, Isaacs logra articular también a los afrodescendientes en ese proyecto de estado nación. Resulta curioso, en relación con esta lectura, que en la traducción al inglés de "María (Harper \& Brothers, Franklin Square, New York, 1890), hecha por Rollo Hodgen, omita, entre otras cosas, la historia de Nay y Sinar, quizás por las barreras raciales imperantes, pese a la necesidad de articularse en discursos homogéneos" (Baéz 102).

María de Isaacs, al ser la novela romántica por excelencia y cuyo público no sólo fue el colombiano sino también y en gran medida, el latinoamericano, logró entrar en esa dinámica de la construcción de comunidades imaginadas. Y más aún al publicarse después de la abolición de la esclavitud en 1851, aunque, como veremos más adelante, ese proceso no se consolidó hasta casi terminado el siglo XIX en el contexto granadino. Para comprender cómo ha sido leída la novela desde la crítica literaria en relación con ese proyecto de construcción de comunidad imaginada, conviene recordar su trama.

La historia de María no difiere mucho de muchas de los relatos de la época: Efraín, hijo de un hacendado en decadencia en el Valle del Cauca, regresa al Paraíso para recordar cómo perdió a María, la hija de un amigo judío como su padre que se la encarga tras su muerte luego de convertirla al catolicismo. Su destino será también trágico al morir de una extraña enfermedad hereditaria antes de poder consumar un amor postergado por el padre de Efraín. Así, entre la familia católica, judíos conversos al cristianismo, exuberantes paisajes de la región,

entre 1821 y poco después de 1851, por las informaciones que encontramos sobre la Ley de Vientres (1821) y la posterior abolición en el capítulo XLIII, tras la compra y manumisión de una de las esclavas por parte del padre de Efraín, narrador de la obra. Para tener un panorama de lo que acontecía en este período, podemos decir que después de la independencia de 1819, promulgando la República de Colombia y hasta 1830, con el final dela unificación panamericana y la muerte de Bolívar, surge la República de la Nueva Granada fue el nombre que fue el nombre que recibió la república unitaria creada por las provincias centrales de la Gran Colombia tras la disolución de esta en 1830. Mantuvo ese nombre desde 1831 hasta 1858, cuando pasó a llamarse Confederación Granadina (1857-1861) y hasta varios levantamientos contra el gobierno conservador, para llegar a la época del nuevo régimen liberal de los Estados Unidos de Colombia. 
esclavos felices y bien tratados por la familia del protagonista, no hay muchas diferencias con la trama y asuntos tratados en otras novelas del mismo período. Así, al representar esa gran novela del Romanticismo y en virtud de los relatos de nación que se estaban construyendo por la época, se pudiera pensar en el proyecto político o la idea de nación que estaba implícita en su narrativa. Al respecto, Doris Sommer nos advierte sobre la falta de él, a diferencia de otras novelas romántica en el resto de Suramérica:

El hecho de que la obra culmine trágicamente no es de por sí pesimista, pues otras novelas de la época, entre ellas Francisco (Cuba, 1839), Sab(Cuba, 1841), Amalia (Argentina, 1851), Iracema (Brasil, 1865), Aves sin nido (Perú, 1889), y Cumandá (Ecuador, 1879) recurren a la tragedia para animar un programa positivo que evite tragedias por venir. Mientras suscitan nuestra simpatía por los amores entre héroes y heroínas, estas obras también localizan un abuso social que obstaculiza el amor. Por lo tanto, apuntan hacia un estado ideal, tanto político como sentimental, que ha de producirse cuando se supere el obstáculo. De manera implícita, y a veces abierta, esas novelas exigen una solución posible para el romance fallido (léase también para el progreso nacional y la productividad) (Sommer 4).

Sommer apunta que falta de un programa político que logre brindar una solución de homogeneidad a la naciente Nueva Granada. Más aun, cuando en otros países el héroe o la heroína era de origen indígena (Iracema, Cumandá, etc.) y unas pocas veces afrodescendiente (Sab). Diferimos de dicho planteamiento al afirmar la existencia de los capítulos del XL al XLIV en los que Efraín narra la historia de una de Nay antes de que muera, donde el espacio de la narración en que la problemática racial y las posturas frente a abolición vendrían a darse más claramente, aunque como una historia secundaria que además cumpliría con la función de anunciar el fin trágico de los protagonistas. Allí asistimos a la narración de Efraín sobre Nay quien, desde la infancia del héroe, le contaba la historia de cómo fue apresada en las costas africanas y cómo perdió a su padre y esposo - ambos reyes en su país - y por vueltas del destino fue conversa al cristianismo - otro tópico del movimiento romántico. Posteriormente, habría de ser embarcada en esos oscuros 
navíos esclavistas, traída a Cartagena y llevada al Atrato, donde sería comprada por un norteamericano y luego salvada y manumisa por el padre de Efraín, que sólo la quería de aya para María, la protagonista de la novela. Evidenciamos entonces, el esbozo de un proyecto político, a pesar de que no encontremos en la trama una sombra de las múltiples guerras entre conservadores y liberales por el poder y sus desencuentros en torno a la abolición de la esclavitud y la imagen de nación que cada uno tenía.

\section{El lugar de la autoría desde una mirada liminar: el origen judío de Isaacs y su ambigüedad racial}

Como buen hijo del siglo XIX, Jorge Enrique Isaacs Ferrer habría de representar casi todas los intempestivos cambios y ambigüedades de este siglo: él mismo fue hijo de un emigrante inglés y de origen judío, militó con los conservadores al ser heredero de haciendas, habría de mostrarse abolicionista ya en la escritura de su obra María y detentar un cargo público como subinspector de obras entre Cali y Buenaventura durante el gobierno liberal de Mosquera; fue diplomático en Chile, participó en las constantes guerras civiles entre liberales y conservadores que fueron la nota característica de aquel período en el Continente americano y viajó por la geografía colombiana. Todo esto, le dio la oportunidad de conocer la antropología del país, "publicando en 1887 un Estudio sobre las tribus indígenas del Estado de Magdalena, antes provincia de Santa Marta" (Chouciño 7). Hablamos de un lugar de autoría liminar donde se funde el ideal del siglo XIX, pero donde también gravitan los fantasmas de una infancia en el mundo señorial y patriarcal de la hacienda azucarera al que no puede renunciar, así ya esté caduco hacia finales de ese siglo en el país.

$\mathrm{Su}$ ambiguo recorrido vital y su temprana vocación de etnógrafo, sumado a las historias que talvez escuchó de su propia aya ${ }^{3}$ en la

${ }^{3} \mathrm{Al}$ respecto. Se habla de la esclava en la que probablemente se basó Isaacs para construir a su personaje Nay: Pero concentrémonos en el personaje de Nay. Quien fuera la persona que inspiró el personaje de Juan Ángel, esclavo de la hacienda El Paraíso, nos brinda un testimonio que permite imaginar lo que significó la diáspora para Nay. Este testimonio data de 1897, dos años antes de la muerte de Juan Ángel: «Mi madre se llamaba Isidora, le contaba a las otras esclavas y a las sirvientas libres de la hacienda que ella había sido traída muy jovencita de por allá de los lados del mar, del país de Guinea, y agregaba que su padre era un gran jefe. Cuando las niñas del patrón Jorge bajaban a las haciendas del valle y mi madre veía las peinetitas de oro que ellas se ponían a uno y otro 
infancia (imagen quizás de la Nay que aparece en María) hacen que aparezca la primera referencia a los relatos sobre la diáspora en el país, relatos evidenciados en el personaje de la esclava manumisa. Nos queda entonces por revisar la obra y cómo se tejen esas apariciones de los esclavos en el relato de Feliciana-Nay, la amistad con Juan Ángel y el matrimonio de Bruno y Remigia, como recortes que escogemos para analizar cómo se construyen estos personajes y si después de todo se insertan en la comunidad imaginada del naciente país.

\section{La narración: Efraín, un sujeto de enunciación limitado}

El sujeto de enunciación en la novela es un narrador limitado, en primera persona, que nos permite ver el universo simbólico frente a las mujeres y a los afrodescendientes. Un universo que pretendía mostrar el mundo casi bucólico de los señores y los esclavos donde las mujeres y los esclavos eran felices, mostrándose acordes con las jerarquías y subjetividades que se esperaba de ellos. Observemos algunos apartados de la obra para notar esto:

En mi ausencia, mi padre había mejorado sus propiedades notablemente: una costosa y bella fábrica de azúcar, muchas fanegadas de caña para abastecerla, extensas dehesas con ganado vacuno y caballar, buenos cebaderos y lujosa casa de habitación, constituían lo más notable de sus haciendas en tierra caliente. Los esclavos, bien vestidos y contentos hasta donde es posible estarlo en la servidumbre, eran sumisos y afectuosos para con su amo (...) Pude notar que mi padre, sin dejar de ser amo, daba un trato cariñoso a sus esclavos, se mostraba celoso por la buena conducta de sus esposas y acariciaba a los niños (Isaacs 7).

Los comportamientos de los esclavos y las esclavas son infantilizados bajo la égida de un régimen señorial en el que sólo caben esclavos felices y esclavas con conductas de buenas esposas. Algo similar ocurre en las clases que imparte Efraín, el narrador, a su hermana Emma y a María, como ocurre en este fragmento:

En ocasiones, quehaceres domésticos llamaban la atención a mis discípulas, y mi hermana tomaba siempre a su cargo ir a desempeñarlos,

lado de la cabeza para adornarse el cabello, me decía con tristeza. "Ve, Juan Ángel, de eso mismo era la corona que me ponían a mí en mi país, cuando mi padre daba alguna fiesta” (Fuentes 233) 
para volver un rato después a reunírsenos. Entonces mi corazón palpitaba fuertemente. María con la frente infantilmente grave y los labios casi risueños, abandonaba a las mías, alguna de sus manos aristocráticas sembradas de hoyuelos (Isaacs 18)

Allí es notorio el adjetivo que puede resumir la descripción que hace el narrador de las actitudes en la mayoría de mujeres en la obra, con excepción de las madres, que evocan un recogimiento especial, quizás por la relación que se hace con la virgen del culto católico, algo similar a lo que ocurrirá en la novela de Dos Reis. De modo que mujeres y esclavos son descritos en un panorama patriarcal y altamente paternalista, refrendando esa imagen de comunidad imaginada homogénea y compacta en el proceso de la construcción de la nación colombiana.

Tenemos también las relaciones de amistad entre Efraín y su padre con los esclavos, un leitmotiv que veremos también en Úrsula de Dos Reis, pero con una semanticidad distinta. En la novela de Isaacs se muestra este tópico cuando en el capítulo $\mathrm{V}$ se nos narra el matrimonio de Remigia y Bruno, dos esclavos de la familia:

En la madrugada del sábado próximo se casaron Bruno y Remigia. Esa noche a las siete montamos mi padre y yo para ir al baile, cuya música empezábamos a oír. Cuando llegamos, Julián, el esclavo capitán de la cuadrilla, salió a tomarnos el estribo y a recibir nuestros caballos. Estaba lujoso con su vestido de domingo, y le pendía de la cintura el largo machete de guarnición plateada, insignia de su empleo (...) Pasada aquella mano, que así llaman los campesinos cada pieza de baile, tocaron los músicos su más hermoso bambuco, porque Julián les anunció que era para el amo. Remigia, animada por su marido y por el capitán, se resolvió al fin a bailar unos momentos con mi padre: pero entonces no se atrevía a levantar los ojos, y sus movimientos en la danza eran menos espontáneos. Al cabo de una hora nos retiramos (Isaacs 8,9).

Lo que es descrito en este apartado como una relación casi de amistad entre los hacendados y la pareja de prometidos, en realidad hacía parte de la vida señorial en la época. Era una estrategia para hacer entrar a los esclavos en la nueva religión y a fin de evitar mezclas raciales, pasados los siglos más duros de la Colonia: 
Si bien la familia española constituyó un modelo, «Este modelo no pudo traspasarse sin someterse al trajín de los influjos nativos y del aporte africano que desordenaron muchos de sus perfiles» (Gutiérrez y Pineda, 1999:327). Como anota la autora, durante el periodo colonial el matrimonio entre negros no fue frecuente especialmente por su situación de esclavitud; en ese momento incentivar el matrimonio no motivó a la iglesia frente al esclavo a pesar de la defensa del matrimonio como vía para controlar las mezclas que minaban la jerarquía socio racial. Se podría decir que mientras durante el periodo colonial hubo un afán de bautizar al negro, en el siglo XIX se introduce la idea de que los negros debían practicar el matrimonio católico como vemos en la frecuente cotidianidad del Paraíso, en donde la ceremonia matrimonial de los subalternos cobra vital importancia (Fuentes 226).

Y esa importancia es vital, teniendo en cuenta el proyecto de nación imaginada que venimos notando en la obra. Un proyecto en el que, a las descripciones del paisaje, la riqueza de las haciendas y la relativa armonía entre amos y esclavos, se suma el folclore de los bailes y escenas del Costumbrismo tan frecuentes en la literatura de la época y en este apartado de la novela.

En contraposición a ese relato de nación imaginada, nos resulta particular el caso del relato de Feliciana/ Nay, por ser la memoria, la diáspora y África como lugar simbólico de identidad. Desde nuestra óptica, esto deja entrever una fisura proveniente de la vocación de etnógrafo de Isaacs y de los relatos de infancia que escuchó de su aya Isidora. En ese sentido, es necesario ver cómo a pesar del ambiente de felicidad y armonía entre amos y esclavos, la muerte de la esclava liberta, rompe con ello. Aquí, Efraín, presintiendo su muerte, recuerda las narraciones que escuchó en su infancia, a propósito de la diáspora del personaje. Lo hace justo después de narrar la pérdida de su padre Magmahú y esposo Sinar en África, su conversión al cristianismo allí y su posterior captura, en estado de embarazo, por traficantes esclavistas y llegada a costas granadinas:

En una ocasión en que Gabriela le hablaba del cielo, usó de toda su salvaje franqueza para preguntarle: geles?

¿Los hijos de los esclavos, si mueren bautizados, pueden ser án- 
La criolla adivinó el pensamiento criminal que Nay acariciaba, y se resolvió a hacerle saber que en el país en que estaba, su hijo sería libre cuando cumpliera dieciocho años.

Nay respondió solamente en tono de lamento:

— ¡Dieciocho años!

(...) Nay se mostró indiferente a todo; pero en la tarde, cuando al ponerse el sol se paseaba mi padre por la ribera del mar llevando de la mano a María, se acercó a él con su hijo en los brazos: en la fisonomía de la esclava aparecía una mezcla tal de dolor e ira salvaje, que sorprendió a mi padre. Cayendo de rodillas a sus pies, le dijo en mal castellano:

-Yo sé que en ese país a donde me llevan, mi hijo será esclavo: si no quieres que lo ahogue (Isaacs 150,152).

Llama la atención el sentido del pensamiento criminal que adivina la criolla Gabriela, que no es más que el aborto, estrategia muy común entre las esclavas para evitarle una vida llena de miserias a sus hijos en tierras americanas. La sola mención del asunto en una novela que además pretende, como hemos visto, narrar a la perfección una comunidad imaginada, un proyecto político para lo que será la nación, es ya una suerte de ruptura con el mundo bucólico del amor, los paisajes y la aparente falta de contexto de levantamiento de esclavos, así como las guerras entre conservadores y liberales en disputa del poder en el país. El personaje evidencia entonces, pese al discurso señorial que vemos a través de la obra, una fisura, una pequeña muestra de resistencia, aunque sea desde el discurso de la muerte frente al sistema esclavista. Conviene recordar lo que apunta Foucault al respecto del poder y de la resistencia:

Estas relaciones de poder múltiples atraviesan, caracterizan y constituyen el campo social. Por ello, la resistencia, como respuesta al ejercicio del poder sobre el cuerpo, las afecciones, los afectos, las acciones, es constitutiva de las relaciones de poder, aparece en distintos puntos del entramado social como fuerza que puede resistir al poder que intenta dominarla, pues, la finalidad de este poder es infiltrar cada vez con mayor profundidad la existencia humana, tanto a nivel individual como a nivel de la especie; su objetivo primordial es administrar la vida humana (Giraldo 118). 
Ahí donde el esclavismo pretendía administrarlo todo, hasta la vida humana y comerciar con ella, Nay subvierte esa administración; se levanta como una subjetividad que responde a esos poderes sobre el cuerpo. De esta forma, su capacidad de dar vida, como su capacidad de dar muerte, dan la vuelta al poder en una asunción del destino de su hijo, al sugerir la posibilidad del aborto.

Siguen resultandos esclarecedores los capítulos donde se relata la historia de Nay, desde su viaje como esclava hasta el idílico Valle del Cauca y llegada a la Hacienda el Paraíso, y que con tanta nostalgia narra Efraín. Y bastante paradójicos, como la vida misma del propio Isaacs y su ambigüedad política. En otro apartado, el padre de Efraín nos recuerda una parte del proceso legal e histórico, en la naciente república, para abolir la esclavitud:

Nay supuso que aquella niña era huérfana de madre, y le cobró particular cariño. Mi padre temía confiársela, a pesar de que María no estaba contenta sino en los brazos de la esclava o jugando con su hijo; pero Gabriela lo tranquilizó contándole lo que ella sabía de la historia de la hija de Magmahú, relación que conmovió al extranjero. Comprendió éste la imprudencia cometida por la esposa de Sardick al hacerle sabedor de la fecha en que había sido traída la africana a tierra granadina, puesto que las leyes del país prohibían desde 1821 la importación de esclavos; y en tal virtud Nay y su hijo eran libres. Mas guardóse bien de dar a conocer a Gabriela el error cometido, y esperó una ocasión favorable para proponer a William le vendiera a Nay (Isaacs 151)

El personaje se refiere a la Ley de Vientres de 1821, lo que nos devuelve al recorrido de la abolición que inició desde 1812 con la Constitución de Cartagena y en la cual declaran libres a los esclavos. Misma que se vio interrumpida por la Reconquista española en 1815, para luego pasar a la mencionada Ley de Vientres en 1821 que, de todas maneras, dejaba claro que el esclavo debía trabajar hasta los dieciocho años. Lo inaudito fue el rezago de esta última hasta 1839 , dejando la edad hasta los veintiún años, mientras se presentaban diferentes presiones por levantamientos de cimarrones o esclavos rebeldes y la llegada del gobierno liberal de José Hilario López al poder, con lo que llegó la abolición en 1851. 
Si leemos atentamente el trecho de la obra de cara al contexto neogranadino vemos cómo, a pesar de existir un conjunto de leyes en la nación de esa comunidad imaginada desde el discurso de la Ilustración y la Revolución Francesa, el país llegó hasta finales del siglo XIX para barrer completamente la esclavitud. Y aunque Efraín rememore un tiempo señorial que pronto quedará en ruinas con la pérdida de las haciendas y la muerte de María, es posible que también nos encontremos la mirada de Isaacs, esquematizando los rezagos, tensiones, demoras y paradojas históricas al respecto del proceso de abolición.

En esa misma línea se inscribe el caso de su hijo Juan Ángel o de los esclavos nacidos en tierra americana, pues tras la muerte de Nay/ Feliciana $^{4}$, su hijo pide, quizás como un gesto de amistad y solidaridad, que Efraín le lleve en su viaje a Londres. El padre de éste decide enviarle a estudiar Medicina, quizás previendo, la quiebra y declive de sus haciendas y así, el patriarca, responde positivamente ante la petición de Juan Ángel. No sabemos lo que ocurre después, pues Efraín narra desde la nostalgia y la melancolía su regreso a una hacienda en ruinas que se parecía mucho al país que todavía le apostaba a ese sistema esclavista.

\section{Comunidades imaginadas en Brasil: Úrsula de dos Reis y los márgenes de la ficción unificadora}

Si bien la novela Úrsula (1859) de María Firmina Dos Reis (18251917) entra en la tradición del Romanticismo y con ello en el esquema de las comunidades imaginadas que planteamos desde Anderson "los esclavos huían en el Maranhao de la época, pues nunca aceptaron la esclavitud pasivamente" (Agostinho 57). La autora muestra a esclavos emancipados sólo mentalmente, lo que de todas maneras se contrapone a la visión feliz de los esclavos en Isaacs, con excepción de los espacios porosos de resistencias que vimos en el relato de la esclava Nay.

Pese a ello, apreciar la obra de la autora es importante como un lugar de habla diferente a los lugares de poder autorizados por la homogeneidad de las comunidades imaginadas, a fin de entender sus cercanías o distancias frente a ese proyecto de nación en Brasil. Así, pensar en las mujeres escritoras como excluidas del canon literario ${ }^{5}$ por

${ }^{4}$ Feliciana es el nombre cristiano que adquiere la esclava en tierras americanas.

${ }^{5}$ En el contexto colombiano tuvimos a Soledad Acosta de Samper 1833-1913, sólo que su 
ser mujer negra y escribir desde los márgenes de la sociedad: esclavos (Úrsula de 1859 y La Esclava de 1867) e indígenas (Gupeva de 1862) es el lugar de sus primeras distancias frente al contexto de la época.

Justamente el siglo XIX fue el marco de muchas de estas obras sobre la esclavitud, en virtud de las muchas revoluciones y levantamientos que se venían dando, así como los movimientos independentistas en las colonias. Vemos así, obras como La cabaña del tío Tom, de Harriet Beecher, "la primera novela antiesclavista, seguida de inglesas y norteamericanas como Harriet Martineau, Lydia María Childs y Fanny Kemble, obras en las que se presentaba al esclavo como un estereotipo objetualizado" (Loureiro 18).

Mientras tanto, en Latinoamérica las novelas románticas se desarrollaron al lado de sus historias patrióticas y la élite escribió novelas volcadas hacia la clase privilegiada como el caso de María de Isaacs, entre muchas otras. Úrsula, se convierte en el primer romance antiesclavista en 1859 , escrito además por alguien que no provenía de las élites. Aunque no se puede hablar en términos de novela abolicionista debido a que las leyes para ello se dieron mucho después de la publicación de la novela, es decir, hacia 1888. Así, "se anticipa a los escritores abolicionistas Castro Alves, Joaquim Manuel Macedo y Bernardo Guimarães" (Agostinho 148). Quizás por estas condiciones de su escritura y por su lugar como mujer negra, fue olvidada casi un siglo, "para ser redescubierta por Nascimento Morais Filho en 1975 y llevar a cabo el facsímil hecho por Horácio de Almeida en el mismo año" (Id. 86).

La novela adquiere, entonces, matices muy especiales. Quizás sea la única en América con esas marcas distintiva de ser escrita por una mujer negra. Lo cual llama a seguirla estudiando, a revisarla de cara a la cultura literaria continental y brasilera, ya que sus personajes se ocupan de la memoria, construyendo a África como un espacio de libertad, "diferente a los casos de obras como Vítimas algozes (1869) de Manuel de Macedo, A escrava Isaura (1875) de Bernardo de Guimarães y Mãe (1860) / Demonio familiar (1857) de José de Alencar" (Loureiro 148). Considerando además que esa incursión de la novela femenina que releen el tópico la esclavitud sólo tuvo su apogeo en el siglo XX.

lugar de habla es desde la élite blanca de la época. 
Pese a participar de las comunidades imaginadas al enmarcarse dentro del Romanticismo, Úrsula, al elegir tópicos como un registro formal del portugués y la religión cristiana como defensa ética frente a los abusos de la esclavitud, antepone su lugar de autoría y su mirada liminar como mujer y negra frente a los discursos homogeneizantes de su época:

Sendo assim, essa obra de Maria Firmina dos Reis desestabiliza os padrões vigentes no Brasil oitocentista e, por conseguinte, promove uma desestabilização da identidade nacional, tanto no que se refere à questão narrativa, uma vez que a história da escravidão negra no Brasil é apresentada a partir do ponto de vista interno, quanto no que se refere à questão autoral, visto que foi escrito por uma mulher afrodescendente e de origem humilde, associando-se assim, três padrões de subordinação: gênero, etnia e classe. (Loureiro 133)

\section{Autoria liminar: una maranhense}

Sobre la vida de María Firmina Dos Reis (1822-1917) se conoce poco. Sin embargo, gracias al esfuerzo de Nascimento Morais y a los recientes estudios de la crítica alrededor de la reconstrucción de la historia de una Literatura Afrobrasilera, hoy sabemos que fue hija de João Pedro Esteves y Leonor Felipe dos Reis; negra y bastarda, era prima del escritor maranhense Francisco Sotero dos Reis por parte da madre. En 1830, se mudó con la familia a la villa de São José de Guimarães y "Vivió parte de su vida en la casa de una tía materna bien situada económicamente. En 1847, obtuvo un puesto de Instrucción Primaria en esa localidad y ejerció a como profesora de primeras letras, de 1847 a 1881" (Agostinho 87,88).

Dos Reis enfrentó barreras sociales para ser reconocida en 1859 como novelista. Tengase en cuenta que, además, que se trataba de la primera obra antiesclavista en el Brasil hecha por una mujer:

De acordo com Lobo (2011), por vezes, houve dúvida sobre o pioneirismo de Maria Firmina dos Reis no que se refere à autoria de seu romance Úrsula, uma vez que, no passado, alguns críticos acreditaram que a primeira romancista brasileira teria sido Teresa Margarida da Silva Orta (ou Horta), nascida em São Paulo, em 1711 (ou 1712) e falecida em Belas, Portugal, em 1793. Entretanto, dois fatos merecem ser des- 
tacados: Teresa Margarida saiu do Brasil aos cinco anos de idade, com sua família portuguesa, e nunca mais retornou ao país; além disso, seu romance epistolar (...) Situação semelhante ocorreu quando se cogitou o nome de Nísia Floresta como a primeira romancista brasileira. Nísia Floresta, entretanto, dedicava - se às atividades de tradutora e ensaísta, além de ter escrito obras didáticas curtas e crônicas sobre o Rio de Janeiro e dois livros de viagem, sendo um deles epistolar (LOBO, 2011). Após todas essas investigações historiográficas, concluiu-se que o romance Úrsula, de Maria Firmina dos Reis, assinado sob o pseudônimo de -Uma Maranhense, é, até onde a historiografia literária brasileira encontrou, o primeiro romance de autoria feminina do país, bem como o primeiro romance abolicionista, e o quinto romance publicado no Brasil, tendo seu único exemplar da primeira edição sido encontrado pelo bibliófilo Horácio de Almeida (Loureiro 49,50)

Así, las presentaciones de los periódicos de la época en Maranhão: "no esperan que se trate de una gran autora" (Agostinho 89). Era inevitable que en un contexto en el que se estaban gestando las ideas unificadoras de una nación, no fueran notorias las resistencias desde el mismo lugar de autoría y el punto de vista expuesto en los personajes y trama de la novela. Por eso, María Firmina Dos Reis se yergue como una productora discreta, en palabras del epílogo a la obra que firma como "una maranhense", novela que cabalga a medias entre el siglo XIX de las comunidades imaginadas del Brasil y los discursos subalternos que tendrán un mejor momento poco más de cien años después.

A prática da escrita por mulheres permite uma intervenção na história e na literatura, a partir da produção estética e social do universo narrativo, cuja expressão dialógica com a sociedade ocorre no conflito de vozes oprimidas em ambientes fechados (Loureiro 111)

\section{Una narración en tercera persona: las posibilidades de la focaliza- ción en esclavas y esclavos}

Esta es una novela más o menos típica del Romanticismo. Tenemos una historia principal que gira en torno al amor entre la protagonista Úrsula y Tancredo, ambos hijos de hacendados que, por reveses en el destino del joven, terminan conociéndose cuando este llega a su casa en grave estado de salud. Allí lo rescata el esclavo Túlio, que se convierte 
en gran amigo del protagonista y obtiene la manumisión de su parte. En el trance de la recuperación de Tancredo, surge la historia de amor entre este y Úrsula donde se va conociendo el pasado trágico de varios de los personajes.

Así vemos historias paralelas: la de la esclava Susana, quien ve con ojos críticos la libertad obtenida por Túlio y a través de la focalización narrativa, se conoce su historia de diáspora africana. La de Tancredo, pues la gravedad de sus males se debe a una historia de amor malogrado con Adelaide, suerte de mujer fatal en la novela; la muerte de su madre y la traición de Adelaide al romper su compromiso y casarse con el padre del protagonista. La de Luisa B, madre de Úrsula, quien fue perseguida por su propio hermano, el comendador, al casarse con Paulo B, esposo que dilapidó su fortuna y fue asesinado por su hermano. La de Túlio y la pérdida de su madre por los excesos del comendador Fernando, gran antagonista de la obra al ser la figura del patriarca y esclavista. La de Antero, un esclavo viejo y alcohólico que vive recordando mejores tiempos en su patria África y finalmente, lo que, desde nuestra lectura, consideramos una historia adicional, la de los esclavos de la hacienda Santa Cruz y el realismo con el que es presentada su vida.

La trama central de la novela termina con el amor inconcluso de los protagonistas, la muerte de Túlio, la de Tancredo, la tortura y la muerte de Susana por no colaborar en la enfermiza obsesión del comendador para encontrar y desposar a Úrsula, su sobrina, de quien se ha enamorado. La obra concluye mostrándonos a Úrsula loca, convertida en una suerte de Ofelia shakesperiana y al comendador arrepentido y víctima de los fantasmas de quienes ha asesinado, como en un Macbeth perseguido por sus crímenes, que se entrega al cristianismo y confiesa sus crímenes a la iglesia, al convertirse en un fraile, tras la muerte de su sobrina.

Es de notar que el recurso narrativo que une estas historias paralelas es la narración en tercera persona que se diluye por momentos en varias focalizaciones, al estilo de Flaubert en su famosa Madame Bovary, lo que mostrará a través de esos focos narrativos con un realismo inédito para la época frente al mundo de los esclavos y en relación con otras obras románticas como el caso de María de Isaacs, cuya narración se mostraba más limitada al mundo señorial, a excepción de la historia 
sobre Nay y el tráfico esclavista en el contexto colombiano. Ahí justamente, notamos una elaboración compleja no sólo desde la estética sino también desde la ética en el tratamiento de las descripciones de los esclavos, sin la sombra del estereotipo del esclavo feliz de otras obras o de los proyectos de nación unificadores:

Toda a descrição da personagem denota a transgressão da autora/ narradora, contrapondo discursivamente outras figuras representativas da narrativa. A constituição da personagem desmitifica a imagem simbólica da aristocracia do "bem", pois todos os sentimentos que tiram a nobreza do ser fazem parte de sua identidade (Carneiro 109).

Esa transgresión que se opera desde el ámbito narrativo va a permear niveles éticos en los que se hermana con el sufrimiento de esclavos y esclavas, en un intento prematuro por mostrar identidades subalternas en el siglo del discurso homogéneo y de los nacionalismos. De suerte que nuestro camino analítico va a recorrer, sobre todo, algunas de las historias paralelas a la trama central y algunos trechos de esta misma: la historia de Túlio y su amistad con Tancredo; un recorte de la historia central de Úrsula, Adelaide y la madre de Tancredo y observar las resistencias femeninas. Así mismo, recorrerá las historias de Susana y Antero, en lo que llamaremos la nostalgia de la diáspora, para finalmente, pasar a algunas consideraciones sobre la historia de los esclavos de Santa Cruz y las descripciones de su mundo.

\section{Las potencialidades de la amistad entre amos y esclavos como dis- curso antiesclavista temprano}

Como pudimos ver, en la relación de amistad entre amos y esclavos en María de Isaacs, algunos de estos gestos eran usuales dentro de los límites del paternalismo y aún menos raros, cuando la esclavitud ya había sido abolida en los Estados Unidos de Colombia para su fecha de publicación, en 1867. Ahora será importante hacer un panorama sobre el proceso la abolición en Brasil, para analizar por qué resulta adelantada para su momento histórico la relación entre Túlio y Tancredo.

En Maranhão, provincia altamente dependiente del tráfico esclavista desde la Colonia, el largo camino a la abolición tuvo tentativas 
tempranas y resistencias. Agostinho nos habla sobre la revuelta de La Balaida (1838-1841) "en la que esclavos y liberales se unieron para protestar contra la supresión de la autonomía de la provincia" (21) como en la misma tierra colombiana y el uso que hicieron de ello los criollos como Bolívar. Los esclavos fueron usados en estos enfrentamientos que, una vez superados, volverían a dejar las condiciones de la esclavitud, exactamente iguales. Condiciones que no se transformarían sino lentamente: de la prohibición del tráfico transatlántico en 1850 , hasta 1871 y la ley de vientres, prohibiendo la esclavitud a los nacidos a partir de esta fecha; luego la prohibición de la esclavitud para los sexagenarios en 1885, el inédito, aunque tardío apoyo de la iglesia en 1887 para lograr la libertad, hasta 1888 , fecha de la abolición.

Con ello, que una obra publicada en 1859 ya presentara las tensiones de los esclavos y lo hiciera con estrategias narrativas que permitían conocer sus sentimientos y pensamientos, en una suerte de profundidad psicológica inusitada, mientras las demás obras románticas mostraban estereotipos, puede ser considerado como un hecho prematuro. La amistad entre Tancredo y Túlio puede ser vista como una metáfora para esa transición abolicionista. Metáfora en la que, narrativamente hablando, Túlio tiene un discurso propio sobre el mal que representa la esclavitud, mal que no necesariamente negara las actitudes éticas y morales de los esclavos, en una suerte de discurso contra las teorías racistas de la época:

Senhor Deus! Quando calará no peito do homem a tua sublime maxima - ama a teu proximo como a ti mesmo, e deixara de opprimir com tam reprehensivel injustiça ao seu simelhante! i¿a aquelle que tambem era livre no seu paiz a aquelle que é seu irmao?! Eo misero soffria; porque era escravo, e a escravidão não Ihe embrutecera a alma; porque os sentimentos generosos, que Deos Ihe implantou no coração, permaneciam intactos, e puros como a sua alma. Era infeliz; mas era virtuoso; e por isso seo coração interneceo- se em presença da dolorosa scena, que se Ihe offereceo á vista (Dos Reis 14).

Evidentemente, el sentido narrativo de ese discurso, tempranamente antiesclavista, otorga no sólo condiciones éticas desde el marco del cristianismo, sino que entrega las potencias de una historia propia. 
Una memoria que les dará la suficiente humanidad en ese tránsito a la abolición, como en este apartado donde el personaje cuenta cómo perdió a su madre por los desmanes del comendador Fernando, la figura por antonomasia del patriarca y esclavista en la novela:

Minhas foças eram ainda debeis para comprehender toda a extensão da minha desgraça; e por isso as saudades, que me ficaram, pouco e pouco foram - se - me adormecendo no peito.

Eu estava ja crescido; mas nunca mais havia visto; era nos prohibida qualquer entre-vista.

Um dia, disseram—me: —Túlio, tua mãe se morreo! ¡Ah! Senhor! Que triste cousa é a escravidão (Dos Reis 138)

En ese sentido y si pensamos en María de Isaacs, el único personaje que tiene una historia plena, construida como memoria que le dota de subjetividad, es Nay. En este caso, la autora despliega una estrategia narrativa que es capaza de sobrevolar por varios de sus personajes y dotar de subjetividad a Túlio, a Úrsula y Antero, como lo veremos en el análisis.

\section{Contrastes femeninos en la obra: Entre lo normativo y las discretas resistencias: las madres, Adelaide, Úrsula y Susana}

Los lugares sociales y simbólicos, tanto de los esclavos como de las mujeres, son muy cercanos en la trama de la novela de tal forma que comparten violencias y modos de resistencia frente al poder. Para hablar sobre las mujeres es preciso dividirlas, al menos de manera muy general, frente a sus actuaciones dentro de la trama. Así, encontramos a aquellas que encarnan los opuestos de ángel y demonio, tan populares en la literatura decimonónica, como nos los recordaran Gilbert y Gubar en su obra La Loca del desván y la imaginación literaria del siglo XIX, al decir que con esos opuestos simbólicos "se le niega la autonomía —la subjetividad- (...) que también se convierte en una encarnación de los extremos de la Otredad misteriosa e intransigente que la cultura enfrenta con adoración o temor, amor o aversión" (Gilbert y Gubar 34). Fueron usados especialmente por los escritores para sublimar sus miedos frente lo femenino y en el caso de las escritoras, para definirse a sí mismas, desde la voz de autoridad que entrega la escritura, como 
en el caso de Dos Reis. Ya Agostinho, propuso una división entre "las madres dolorosas y las madres plenas" $(117,118)$, uniendo a las mujeres sin distinción de raza, lo que no valora este tipo de diferencias, cruciales en el contexto y tema de la novela. Además de obviar las discretas resistencias de un personaje tan complejo como lo es Úrsula.

En nuestra división, están de un lado las madres que mueren, literalmente, a causa del sistema patriarcal (la madre de Tancredo, la madre de Úrsula, Susana y la madre de Túlio) y las heroínas que oscilan entre la norma y la desobediencia (Úrsula y María, si queremos continuar con la trama comparativa). De otro lado, se encuentran las mujeres fatales o demonios, que saben cuáles papeles desempeñar para sobrevivir en un mundo hecho para hombres (Adelaide). Como toda clasificación, siempre será más o menos próxima a personajes con subjetividades complejas. Es justo decir que Adelaide, si bien no muere literalmente como es el caso del primer grupo de mujeres, tiene una suerte de muerte que llamaremos provisionalmente emocional, pues sacrifica sus verdaderas emociones por lograr un lugar de poder al lado del padre de Tancredo. Y en el caso de las esclavas, como lo son la madre de Túlio y Susana, estarían en una subdivisión del primer grupo por su condición racial.

De suerte que el primer grupo representa un lugar más o menos común frente a los estereotipos sobre las mujeres, por el leitmotiv de la maternidad, también está presente en la obra de Isaacs, en la madre de Efraín y la madre de María, aunque la primera no muera. En el segundo grupo, como dijimos, la resistencia a su lugar social que lleva a cabo Adelaide, es limitada, por el sacrificio personal que representa casarse con un patriarca como lo es el padre de Tancredo y renunciar a su amor de juventud. $\mathrm{Y}$ en el caso de las madres negras, como lo son la madre de Túlio, Susana y Nay, en María, encontramos ese mismo leitmotiv de la maternidad, tan caro además a un sistema esclavista productor de más mano de obra gratuita.

Con la resistencia subjetiva de Susana, es una liberación de la esclavitud, al menos desde su mente y psicología. El caso de Nay, pese a morir también en la obra, aunque no a causa del sistema esclavista y de la tortura sistemática como Susana, parece abrir la brecha a todas 
esas historias no contadas o al menos todavía ocultas en gran medida al archivo histórico y a la literatura de la época sobre los abortos y asesinatos de hijos para no entregarle más vidas al sistema. Y si bien Nay no cumple con las amenazas, este discurso suyo constituye un ápice valioso, que ahora mismo se está estudiando mucho en el Caribe ${ }^{6}$. En lo que corresponde con las heroínas como María y la misma Úrsula, ambas parecen caber en el molde de las obediencias, bellezas infantiles y angelicales del siglo XIX, con discretas muestras de resistencia a ello, como la enfermedad en María y su pasión, no tan velada por Efraín, así como la huida de Úrsula de su incestuoso tío.

Como representantes de ese sistema patriarcal, encontramos figuras que algunas veces son poco visibles como el caso de María y el padre de Efraín, quien prohíbe la boda de los protagonistas en un intento de separación racial, como lo dice una buena parte de la crítica: "pues María era judía conversa, y habría allí un tema discriminatorio" (Galeano 17) y otras veces representan personajes concretos en Úrsula, como el caso del padre de Tancredo y el comendador Fernando, quienes vienen a ser lugares de violencia sexual, física y simbólica extremas del patriarcado, perpetrada contra los esclavos y las mujeres, indistintamente. Así, concordamos con Loureiro al pensar que este recorrido femenino viene a mostrar a Dos Reis y su obra con resistencia políticas, éticas y estéticas importantes, no sólo para la literatura brasilera, sino continental, en general:

Na figura de Susana, a voz narrativa realiza duras críticas ao sistema escravocrata, especialmente quando a velha escrava relata todos os sofrimentos vivenciados desde sua captura no continente africano até sua chegada ao Brasil. Os relatos acerca da escravidão são contados, nessa obra, a partir do ponto de vista dos próprios escravos (Loureiro 133).

\section{Focalizaciones de la diáspora: resistencia desde la memoria y la memoria como forma de subjetividad}

Como pudimos apreciar en María, esa nostalgia por la tierra africana evidenciada en los capítulos del XL al XLIV en la historia de Nay, viene a darse también e incluso de manera anterior en Úrsula, en el capítulo

${ }^{6}$ Ver Mujer y esclavitud en el cuento "Saeta" de Yolanda Pizarro de Amarilis Hidalgo de Jesús 
IX con la focalización en Susana y luego en el capítulo XVIII con el discurso indirecto de Antero. Susana viene a ser "alter ego de la autora, pero también de la diáspora africana, como memoria" (Agostinho 141) en el difícil camino a la abolición. No obstante, deja claro en sus advertencias a Túlio ante su manumisión, que de nada servirían las libertades individuales sino se opera un cambio profundo en la estructura social. De nuevo, su discurso resulta prematuro y abarcador del largo proceso abolicionista en el Brasil de la época. Ahora bien, el discurso de su diáspora viene a ser muy parecido al discurso de Nay en la novela del autor colombiano, como se nota en el siguiente apartado de la novela:

Vou contar - te o meo captiveiro. (...) Ainda não tinha vencido cem braças de caminho, quando um assobio, que respesentio nas mattas, me veio orientar acerca do perigo eminente, que ahi me aguardava. E logo dois homens appareceram, e amarraram-me com cordas. Era uma prisioneira - era uma escrava! Foi em balde que supliquei ern nome de minha filha, que me restituissem a liberdade; os barbaros sorriamse das minhas lagrimas, e olhavara - me sim compaixão. Julguei enlouquecer, julguei morrer, mas não me foi possivel.... A sorte me reservava ainda longos combates. Quando me arrancaram d'aquelles lugares, onde tudo me ficava - patria, esposo, mãe e filha e liberdade! meo Deos! o que se passou no fundo de minha alma, só vós o pudestes avaliar!..,. Meteram-me a mim e a mais tresentos companheiros de infortunio e do captiveiro no estreito e infecto porão de um navio. Trinta dias de crueis tormentos, e de falta absoluta de tudo quanto e mais necessario a vida passamos n'essa sepultura até que abordamos ás praias brasileiras. Para caber a mercadoria humana no porão fomos amarrados em pé e para que não houvesse receio de revolta, acorrentados como os animaes ferozes das nossas maltas, que se levam para recreio dos potentados da Europa; Davam - nos a agua immunda, podre e dada com mesquinhez, a comida má e ainda mais porca: vimos morrer ao nosso lado muitos companheiros a falta de ar, de alimento e de agua. E horrível lembrar que creaturas humanas tractem a seos semelhantes assim e que não lhes doa a consciencia de leval—os á sepultura asphixiados e famintos! Muitos não deixavam chegar esse último extremo — davam—se a morte (Dos Reis 92,94). 
De nuevo, la historia del rapto en costas africanas, el embarque en los navíos negreros, la pérdida de los padres, esposos e hijos y el trato de "animales" que les dan los traficantes; construyen ese viaje físico y simbólico que a través de su expresión en el relato y de cara a la recuperación que se dará de ellos, bien avanzado el siglo XX, podrían constituir todo el sentido de una novela de formación de la historia del afrodescendiente en las américas. Nótese además que el suicidio, así como las amenazas del aborto y asesinato de los hijos en Nay, vienen a narrar esa historia de los esclavos y esclavas, ya muy distante del estereotipo del esclavo feliz. En ese orden de ideas, Antero es mostrado entre la nostalgia y la resignación. También él relata su propia visión frente a esa África de la que fue separado:

Pois bem- "continuou o velho"- no meo tempo bebia muitas vezes, embriagavame, e nimguem me lanzaba isso em rosto; porque para sustentar meo vicio não me faltavam meios.

- Perfeitamente, — «retorquio Túlio, fingindo sorrir-sse.

-Pois Ouça - me, senhor conselheiro: na minha terra há um dia em cada semana, que se dedica a festa do fetixe, e em esse dia, como não se trabalha, a gente divertese, brinca e bebe. ¡Oh!! lá então é vinho do palmeira mil vezes melhor que cachaça, e ainda que tiquira. (Dos Reis 172,173)

Finalmente, vemos las descripciones realistas no sólo de la trata, sino de las torturas, los instrumentos para ello y el trabajo esclavista llevado a su máxima representación en la hacienda Santa Cruz:

(...) Porque os desgraçados escravos do commendador, espectros ambulantes, não despunham de uma só hora no dia, que podessem dedicar em benefício de suas moradas; a noite trabalham ordinariamente até ao primeiro cantar do gallo. Esfaimados, semi-nús, espancados cruclmenle, suspiravam pelas duas ou tres houras desse somno fatigado, que lhes concedia a duresa de seo senhor. Desgraçados! Que até a hora das tevas e do repouso, á hora em que a brisa geme apaixonada, como amante, que anhela o ardente halito do seo adorador, em que a herva escuta o segredo terno da viracão, em que o cantor da espessura afaga o plumigero habitante de seo ninho amoroso, um momento de socego e amor lhes é vedado! Não há descanso para o seo corpo, nem tranquilidade para seo espirito desvairado pelo terror de tantos e tão 
continuos soffrimentos! Misero escravo !!!... Tantas dores há em seo coração; e nós as não comprehendemos! (Dos Reis 136)

Descripciones de fatiga, dureza, falta de sosiego y sufrimientos incomprendidos como explica la voz narrativa al final del fragmento. La novela, a través de su estrategia narrativa, descripciones y de cara al contexto anterior a 1888, muestra un paraíso bastante lejano: la abolición de los estereotipos raciales, tarea que será ya del siglo XX y de la posteridad. Lejos estamos del paraíso perdido de María, de la nostalgia por un mundo señorial. Aquí hay nostalgia, pero de una África ya perdida por el negocio de la trata.

\section{Conclusiones}

Desde la lejanía temporal, mas no desde el abandono total de los preconceptos raciales, de clase social o género; vemos que en la Literatura Brasilera hay una necesidad de transformar esas ideas sobre la comunidad imaginada o constructo de nación en el Brasil contemporáneo:

Se a literatura brasileira contemporànea não está mais empenhada em representar à nação como totalidade, fundamentada no pensamento eurocéntrico da universalidade a que Benedict Anderson associa a um tempo homogêneo, e vazio, cabe preguntar como então representa-la em tempo heterogéneo (Cordeiro 41)

Ào lidar de modo performático com o espectro da nação, em que esta se torna um espaço liminar de signifição, a propia herencia cultural se desestabiliza, porque não mais homogênea, âgora marcada pela temporalidade do entrelugar (Id. 50)

Entonces, los modos de representar, literariamente hablando, este tiempo heterogéneo comenzaron desde estas narrativas decimonónicas. Aunque sea como discretas formas de resistencia y a caballo entre lo homogéneo y lo heterogéneo, tanto en el caso de María de Isaacs, con sus fisuras en la idea de nación y en la novela de Dos Reis, con su inclusión de otras visiones de mundo. 


\section{Referencias}

Agostinho, Regia. «A escravidão em Maranhão. María Firmina Dos Reis e as representações sobre escravidão e mulheres no Maranhão da segunda metade do século XIX. 2013.» Tese Doutorado em História Econômica. São Paulo: Faculdade de Filosofia Ciências Humanas, Universidade de São Paulo, 2018. Digital.

Anderson, Benedict. Comunidades imaginadas. Reflexiones sobre el origen y la difusión del nacionalismo cultura. México : Fondo de cultura económica,, 1993. Digital.

Baéz, Marcelo. «La historia de Nay y Sinar de Jorge Isaacs y Sab de Gertrudis Gómez de Avellaneda: un contrapunto.» Kipus Revista Andina de letras (2013): 101-114. Digital.

Carneiro, Ana Carla. «Autoria, devir e interdição: os "entre-lugares" do sujeito no romance Úrsula.» Dissertação. (Mestrado em Estudos da Linguagem). Goiás, Catalão: Departamento de Letras, Universidade Federal de Goiás, 2015. Digital.

Chouciño, Ana. Biblioteca Virtual Miguel de Cervantes. 2009. Digital. 2 de junio de 2018.

Cordeiro, Renato. «Herança, espectros e resíduos: imaginar a nação em tempos heterogêneos.» Resende, Beatriz y Ettore Finazi-Agró. Possibilidades da nova escrita literária no Brasil. Rio de Janeiro: Revan, 2014. 39-57. Impreso.

Dos Reis, María Firmina. Úrsula, Edição fac-similar. Maranhão: Biblioteca Pública Benedito Leite, 1975. Digital.

Fuentes, Nara. «Nos damos por convidados, la voz de los esclavos en la hacienda El Paraíso.» Tabula Rasa (2006): 217-240. Digital.

Galeano, Juan Camilo. «Repensando a María: esclavismo, antisemitismo y machismo en la obra de Jorge Isaacs.» Revista Ratio Juris (2011): 17-36. Digital.

Gilbert, Sandra y Susan Gubar. La loca del desván. La escritora y la imaginación literaria del siglo XIX. Madrid: Ediciones Cátedra, 1998. Impreso.

Giraldo, Reinaldo. «Poder y resistencia en Michel Foucault.» Tabula Rasa (2006): 103-122. Digital.

Isaacs, Jorge. María. Barcelona: Red Ediciones SL, 2013. Digital .

Loureiro, Bárbara. «Visões da escravatura na América Latina: Sab e Úrsula.» Dissertação. (Mestrado em Letras). Santa Maria RS: Centro de Artes e Letras, Universidade Federal de Santa Maria, 2013. Digital.

Mejía, Eduardo André. «ngel Rama y Antonio Candido: la integración del Brasil en el sistema literario latinoamericano.» Literatura: teoría, historia, crítica (2014): 165-192. Digital. 


\section{JuAna SAÑUdo CAicedo}

Sommer, Doris. «El mal de "María": (con)fusión en un romance nacional.» Sommer, Doris. Ficciones fundacionales: las novelas nacionales de América Latina. Bogotá: Ediciones Fondo de Cultura Económica, 2004. 225262. Digital. 